\title{
Manchester Manifesto on the History of Science and Technology
}

On the occasion of the largest global meeting of historians of science, technology, and medicine we, the officers and members of the Division of the History of Science and Technology of the International Union of the History and Philosophy of Science and Technology affirm the following:

(1) Science, technology, and medicine have been abiding features of humanity for millennia and are integral parts of society and culture throughout the globe.

(2) Scientific, technical, and medical literacy is a public good.

(3) We support the study of nature and strive to render it comprehensible to the scientific community and to the wider public through conscientious scholarship and public outreach activities in the human family's many languages.

(4) Historical scholarship on science, technology, and medicine should seek a full and nuanced accounting of the growth, progress, problems, and prospects of these essential human activities. This supports awareness that science, technology and medicine, when rightly prosecuted, are a public good.

(5) Historians of science, technology, and medicine can build bridges between different cultures through collaboration and examination of different perspectives, heritages, and styles of thinking.

(6) An understanding of the history of science, technology, and medicine enhances the teaching of general history as well as the teaching of the methods and context of science, technology, and medicine.

(7) The artefacts of science, technology, and medicine constitute an essential material heritage of humankind. These materials must be preserved, interpreted, and further developed by professionals with a deep knowledge of their cultural significance.

Therefore, in the interests of global betterment and putting knowledge to work, the united participants of the $24^{\text {th }}$ International Congress of History of Science, Technology, and Medicine held at Manchester, UK, in July 2013 declare:

The history of science, technology, and medicine should be supported and financed regularly and continuously by state and private institutions to ensure that younger generations are familiar with their scientific, technological, and medical heritage as interpreted by appropriately-trained historians. 
The history of science, technology, and medicine merits prominent integration into the curricula of high schools, colleges, and universities. Local and national practices should guide this integration.

Comments by Peeter Müürsepp: In July 2013, about 1,700 historians of science from all over the world met in Manchester at the XXIV World Congress of the History of Science, Technology and Medicine. During the multiple discussions, the congress participants acknowledged a common concern about their discipline. The essence of the concern is the fact that history of science quite frequently is not accounted for as a discipline in its own right among other academic fields. Historians of science, technology and medicine are striving for the recognition of their field of interest to be considered a regular academic discipline deserving to be taught at schools and universities and recognized as a relevant research field worth of continuous attention. 